25/45 had a prior CT report indicating malignant pathology, whereas 20/45 had a CT reporting no evidence of pleural malignancy (sensitivity of CT for a diagnosis of malignant pleural disease $=55.6 \%, 95 \%$ CI $41.0 \%$ to $70.1 \%$ ). Of the 42 cases with a thoracoscopic biopsy demonstrating benign pathology, 9 had CTs reporting malignant pathology (specificity for $\mathrm{CT}=78.6 \%, 95 \% \mathrm{CI}$ $66.1 \%$ to $90.9 \%$ ).

Conclusion CT appears to be less sensitive (56\%) than previously reported, with a specificity (79\%) similar to the previous literature. This difference may reflect changing patterns of disease or changes in the use of invasive biopsy techniques. The data suggests that the use of CT alone in determining which patients should have invasive pleural biopsies should be re-evaluated, and further studies to define the diagnostic pathway are now required.

\section{S20 MEDICAL THORACOSCOPY IS SAFE AND EFFECTIVE IN PATIENTS WITH SMALL OR NO PLEURAL EFFUSIONS}

doi:10.1136/thoraxjnl-2012-202678.026

AA Soosay, R Syyed, SH Baird Monklands. Hospital, Airdrie, Lanarkshire, United Kingdom

Introduction Current BTS guidelines recommend the utilisation of medical thoracoscopy (MT) for cytology negative, exudative pleural effusions. A large pleural cavity is required between the lung and chest wall for safe MT. The presence of little or no pleural fluid, despite there being pleural disease present, makes the procedure technically challenging with a higher potential for complications, bleeding and failure of the procedure.

Objective We compare the safety and efficiency of MT performed in patients with small or absent pleural effusions, with patients with moderate or large effusions.

Methods A retrospective review of case notes, radiology and pathology reports of patients who underwent MT between January 2010 and March 2012 was conducted. All procedures were performed or assisted by a level II thoracoscopist with the aid of live ultrasound scanning (USS). Pleural effusion size was estimated using chest $\mathrm{x}$-ray and bedside USS. A small effusion was defined as blunting of the costophrenic angle only on chest x-ray and less than $100 \mathrm{ml}$ fluid estimation on USS. Patients were divided into two groups based on effusion size (absent or small effusion and moderate or large effusion). Data was collected and analysed for minor and major complications and diagnostic yield.

Results 43 MT were performed during the period. $88 \%$ of patients were male $(n=38)$. The mean patient age was 70.1 years (SD 8.69). $41.9 \%$ patients had absent/small effusions $(n=18)$. There were no major complications documented in either group. The minor complication rate was $8 \%$ in the moderate/large effusions group $(n=2)$ and $11 \%$ in the absent/small effusions group $(n=2)$. The minor complications noted were trapped lung, surgical emphysema, wound infection and haematoma. The diagnostic yield was $96 \%$ in the moderate/large effusions group $(n=24)$ and $94 \%$ in the absent/ small effusions group $(n=17)$.

Conclusions Despite its technical challenges, MT can be performed safely and effectively with minimal minor complications and high diagnostic yield in patients with small pleural effusions and even when no fluid is present when performed by thoracoscopists with appropriate experience level.

\section{S21 IS THERE A CORRELATION BETWEEN LUNG FUNCTION VALUES AND CARDIOPULIMONARY EXERCISE OUTCOME?}

doi:10.1136/thoraxjnl-2012-202678.027

'M Gillion, ${ }^{2} \mathrm{M}$ Homsy, 'B Lams, 'E-S Suh, 'M Dasaolu. 'Guy's and St Thomas' NHS Foundation Trust, London, England; '²ings College London, London, England
Introduction Cardiopulmonary Exercise testing (CPET) has become an important tool for perioperative assessment as it may identify patients at risk of postoperative cardiopulmonary complications. Older (1) recommended that an Anaerobic Threshold (AT) $<11$ or $>11 \mathrm{ml} / \mathrm{min} / \mathrm{kg}$ can be used to stratify post-operative treatment in colorectal patients (ITU, HDU or ward). The BTS guidelines (2) recommend that a Peak VO2 (PVO2) $<15$ or $>15 \mathrm{ml} /$ $\mathrm{min} / \mathrm{kg}$ can be used as a risk assessment in thoracic surgical patients. However, CPET can be difficulty to carry out. This study was undertaken to determine whether selected lung function values correlated with CPET outcome, so that they could be used as an alternative to AT and PVO2.

Method 500 pre-operative colorectal (388) and oesophageal (112) patients attending the Lung Function Department were analysed. Spirometry and Gas Transfer were performed to assess lung function. CPET was performed on a cycle ergometer to calculate PVO2 and AT.

Results The area under the curve (AUC) of a Receiver Operating Curve (ROC) analysis was carried out on the 500 patients. This compared percent predicted FEV1, FVC, TLco and Kco values to PVO2 and AT.

Abstract S21 Table 1

\begin{tabular}{lcccccc}
\hline AUC & $\begin{array}{c}\text { FEV1 (\% } \\
\text { Predicted) }\end{array}$ & $\begin{array}{c}\text { FVC (\% } \\
\text { Predicted) }\end{array}$ & $\begin{array}{c}\text { TLco }(\% \\
\text { Predicted) }\end{array}$ & $\begin{array}{c}\text { Kco }(\% \\
\text { Predicted) }\end{array}$ & PV02 & AT \\
\hline PV02 & 0.560 & 0.557 & 0.721 & 0.625 & 1.00 & 0.894 \\
AT & 0.547 & 0.568 & 0.643 & 0.555 & 0.877 & 1.000 \\
\hline
\end{tabular}

Discussion Our findings indicated that analysis of lung function variables cannot reliably predict PVO2 or AT outcome. However, of the variables recorded, TLco was the best marker for predicting a $\mathrm{PVO} 2>15 \mathrm{ml} / \mathrm{min} / \mathrm{kg}$ (0.721). When the cut-off for TLco was set at $80 \%$ predicted it had a sensitivity and 1 -specificity of $62 \%$ and $24 \%$ respectively.

Interestingly, there was a significant correlation between AT and PVO2 (0.894), suggesting that AT can be used as a predictor of PVO2. If the cut-off for AT was set at $11 \mathrm{ml} / \mathrm{min} / \mathrm{kg}$; the sensitivity was $91.7 \%$ and the 1 -specificity $37.7 \%$. However if the cut-off was adjusted to $12 \mathrm{ml} / \mathrm{min} / \mathrm{kg}$; the sensitivity was $77.3 \%$ and the 1-specificity was $13.7 \%$.

Conclusion These results suggest that in pre-operative assessment of patients undergoing thoracic surgery, an AT $>12 \mathrm{ml} / \mathrm{min} / \mathrm{kg}$ could be used as an alternative measure if the patient was unable to achieve a PVO2 $>15 \mathrm{ml} / \mathrm{min} / \mathrm{kg}$.

\section{Reference}

1. Older(1999). Cardiopulmonary exercise testing as a screening test for perioperative management of major surgery in the elderly. Chest; 116; 355-62.

2. BTS Guidelines on the selection of patients with lung cancer for surgery (2001). Thorax 56:89-108.

\section{S22 THE EFFECT OF NEEDLE GAUGE ON CHARACTERISATION OF HISTOLOGY SAMPLES AT ENDOBRONCHIAL ULTRASOUND- GUIDED TRANSBRONCHIAL NEEDLE ASPIRATION (EBUS- TBNA)}

doi:10.1136/thoraxinl-2012-202678.028

A Jeyabalan, ARL Medford. North Bristol Lung Centre, Southmead Hospital, Bristol, UK

Introduction Endobronchial ultrasound-guided transbronchial needle aspiration (EBUS-TBNA) is a minimally invasive mediastinal node sampling technique used for lung cancer staging and 